\title{
WAKE CHARACTERIZATION IN ROW ARRAY OF HYDROKINETICS TURBINES
}

\author{
V.S. Britto, ABSTRACT \\ R. C. F. Mendes, \\ A. C. P. Brasil, \\ This study aims to obtain wake information, which passes through a linear \\ array of turbines. Is presented a numerical approach to observe what effect \\ can be obtained from a 2.2 meters turbines set. The linear array parameters \\ and T. F. Oliveira \\ Universidade de Brasília. Faculdade de \\ were based on the Hydro-k project, in which two unconfined in-line rotors \\ were used. The studies were performed by analyzing three variables: mean \\ normalized velocity, turbulence kinetic energy and turbulence intensity. It \\ was noted that the iteration between the rotors alters the flow on the array of \\ Tecnologia. Laboratório de Energia e Ambiente \\ turbines increasing the center speed. \\ CEP 70910-900 Brasília-DF. Brasil \\ viniciusbrto@hotmail.com \\ Received: April 14, 2018 \\ Revised: May 11, 2018 \\ Accepted: May 31, 2018 \\ Keywords: Hydrokinetic turbines, array of turbines, wake characterization
}

\section{NOMENCLATURE}

A rotor Area, $\mathrm{m}^{2}$

$\mathrm{C}_{\mathrm{p}}$ power coefficient

TSR tip speed ratio

$\mathrm{P}_{\text {ext }}$ power extracted, $\mathrm{W}$

$\mathrm{Re}$ reynolds number

$\mathrm{D}$ rotor diameter, $\mathrm{m}$

$\mathrm{H}$ domain height, $\mathrm{m}$

$\mathrm{L}$ domain length, $\mathrm{m}$

W domain width, $m$

$\mathrm{k}$ turbulence kinetic energy (TKE), $\mathrm{m}^{2} / \mathrm{s}^{2}$

$\bar{u}(x)$ mean time velocity, $\mathrm{m} / \mathrm{s}$

I turbulence intensity,

m total mass of the arrangement, kg

$\mathrm{U}_{\infty} \quad$ free stream velocity, $\mathrm{m} / \mathrm{s}$

$\mathrm{u} / \mathrm{U}_{\infty}$ normalized velocity, $\mathrm{m} / \mathrm{s}$

p pressure, $\mathrm{N} / \mathrm{m}^{2}$

u' velocity fluctuation, $\mathrm{m} / \mathrm{s}$

$\mathrm{t}$ time, $\mathrm{s}$

$\mathrm{u}_{1}, \mathrm{U}_{2}, \mathrm{u}_{3}$ velocity components, $\mathrm{m} / \mathrm{s}$

$\mathrm{x}, \mathrm{y}, \mathrm{z}$ cartesian coordinates, $\mathrm{m}$

\section{Greek symbols}

$v \quad$ fluid kinematic viscosity, $\mathrm{m}^{2} / \mathrm{s}$

$\rho$ density, $\mathrm{kg} / \mathrm{m}^{3}$

$\omega$ dissipation rate of turbulence

\section{Subscripts \\ ext extracted \\ $\infty \quad$ free stream \\ p power}

$$
\begin{array}{ll}
\infty & \text { free stream } \\
\text { i } & \text { iteration counter }
\end{array}
$$

\section{INTRODUCTION}

The use of energy from hydrokinetic turbines has grown due to the demand for renewable energy sources. The search for ways to produce energy encourages the development of new technologies. However, the implementation of hydrokinetic farms requires lots of researches about the efficiency of the machines. Horizontal axis turbines works transforming kinetic energy into electricity. The classical model to obtain the extracted power $\left(P_{e x t}\right)$ from a free-flow turbine is given by:

$$
P_{e x t}=\frac{1}{2} \rho A U_{\infty}^{3} C_{p}
$$

where $P_{e x t}$ is the mechanical power extracted by the machine, $\rho$ the density of the analysis fluid, $\mathrm{U}_{\infty}$ is the free stream velocity and $C_{p}$ represents the dynamic efficiency of the turbine (Power Coefficient). The conversion capacity of the turbines depends on several factors, such as flow velocity, design of the blades and the wake produced by the rotor.

Through the analysis of aerodynamic behavior and based on the theory of conservation of linear momentum, Betz (1920) defined that the maximum energy converted by a turbine is equal to $16 / 27$. With the Betz limit theory it was possible to have an estimate of the viability of the free-flow turbine projects. Glauert (1935) showed that the real limit is 
slightly less than that proposed by Betz.

With the implementation of axial, wind or hydrokinetic turbines, energy efficiency has become a focus for researchers. However to increase the conversion capacity, the Betz limit should be exceeded. This motivation has initiated several studies to optimize integral parts such as blades, diffusors and generators. Investigations about the wake, formed downstream turbines, gained relevance in the scientific environment (Wilson, 1974; Crespo, 1990), believing that the variation of the flow can influence the performance of the machine in highscale power generation (hydrokinetic farms).

The need to study wake effects grows as more complex theories arise. Predictive models were created by using analytical expressions that estimate the kinetic energy of turbulence and its dissipation (Ainslie, 1988). Other methods had succeed by mixing analytical expressions, from experimental work, to estimate and improve the contributions of each term of the turbulent stress tensor and the velocity deficit on the wake (Gomez-Elvira et. al., 2005; Bastankhah and Porté-Angel, 2014).

The numerical methodology allowed to extract more information from the wakes, including distributions of induction factors and vortex structures. The simulations of Sørensen et al. (2002) were of great relevance and served for several analyzes, such as numerical validation like NREL's case. Also, working on the NREL Phase VI, Potsdam and Mavriplis (2009), Carcangiu (2008), Mo and Lee (2012) got good results in the computational simulations using SST turbulence model.

Recent works indicates significant improvements in power extraction using turbine arrangements. The arrangement tend to cause a blocking effect on the channel, and modify the behavior of the wake. This effect causes the fluid to pass through the turbine and induce a secondary flow, this interaction causes the turbine back pressure gain to be lower, resulting in an increase in the power gain (Cooke et. al., 2016).

Sanderse et al. (2011) and Mehta et al. (2014) presented detailed reviews of the state-of-the-art of numerical turbine simulations and their aerodynamics wakes. Efficient techniques for rotor and flow simulation, turbulent models and a description of the composition and formation of the turbulent wakes are discussed. Troldborg et al. (2010) and Kumer et al. (2016) present simulations, combining LES methodology with actuator disk, of the wake characteristics for a wind turbine operating at different blade speeds (TSR). The behavior of the nearby and distant wakes for velocity, turbulence kinetic energy (TKE), vortex structures and instabilities were reported. The authors concluded that instability is an intrinsic part of the dynamics of a rotor flow, requiring no external turbulence to transition from a laminar to a turbulent flow, depending only on the conditions adopted.
Mycek et al. (2016) presents a numerical investigation for the calculation of marine turbines current arranged in farm formation. Through iterative approaches and numerical tests some applications (specifically wake calculations) are presented in a farm, together with a quantitative evaluation of the computational time savings brought by the iterative predictive approach.

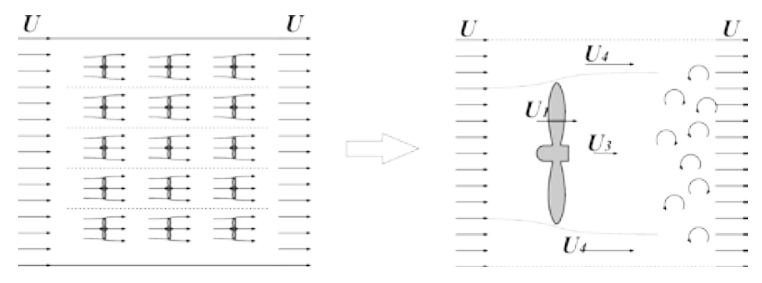

Figure 1. Hidrokinetic farm scheme.

Figure 1 shows a hydrokinetic farm in a canal, with spaces between turbines, shown in a linear arrangement forming a grid. Adjacent turbines create virtual barriers, signaled by dotted lines. These barriers improve the flow through the turbines relative to the slower flows through the turbines; therefore $\mathrm{U}_{4}>\mathrm{U}>\mathrm{U}_{1}>\mathrm{U}_{3}$ (Vennell, 2010).

Chawdhary et al. (2017) presented numerical and experimental cases in a unique mechanism of interaction of the wakes. The author characterizes that the unique flow condition, given the configuration of the turbines, indicates the presence of the Venturi effect in the turbines downstream. This change in flow characteristics directly influences the power output, varying the benefits according to the flow condition.

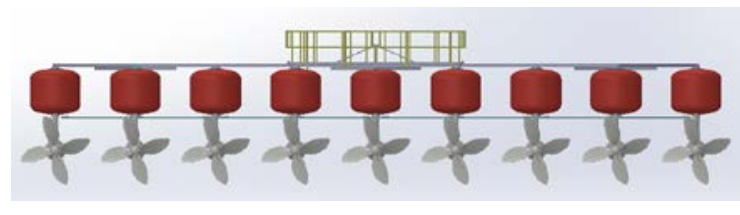

Figure 2. Row arrangement of floating turbines.

The present work is inspired by the recent research on hydrokinetic turbines conducted by the Energy and Environment Laboratory of the University of Brasília (LEA-UnB). Brasil Jr. et al. (2016) performed a numerical study with a set of row-arranged hydrokinetic turbines (linear arrangement), shown in Figure 2, evaluating and comparing performance with the Blade Element Momentum (BEM) methodology. The investigation and characterization of a turbulent flow between two hydrokinetic turbines is based on the geometry of "hydrokinetic farm" presented in Brasil Jr. et al. (2016) for Hydro-K project. Consequently, the aim of this work is to study the reasons of the increase of the speed of the flow between two turbines and the benefits in the power. 


\section{COMPUTATIONAL PROCEDURE}

Computation fluid dynamics approach was used to perform simulations of flow through the rotors. Navier-Stokes equations were solved using unsteady Reynolds average (URANS) methodology, based on the ANSYS-CFX solver, in order to obtain the transient behavior of the flow. Turbulence model k$\omega / \mathrm{SST}$ was employed in the domain to model the wake region. The domain was divided in two subdomains, first an external and stationary box shaped. The other is an internal rotating sub-domain that takes form of a cylinder and envelops the entire rotor. The stationary domain varies its dimensions for each case as presented in Table 1, while the rotating domain is fixed.

Table 1. Stationary domain dimensions.

\begin{tabular}{llll}
\hline & Height [m] & Width [m] & Length [m] \\
\hline $\begin{array}{l}\text { Stand } \\
\text { Alone }\end{array}$ & 17.6 & 17.6 & 30.8 \\
\hline $\begin{array}{l}\text { Row } \\
\text { Array }\end{array}$ & 22 & 24.2 & 30.8 \\
\hline
\end{tabular}

The option to enlarge the domain in row array case was to prevent a flow constriction due the addiction of one more turbine. The domains shape for simulations is shown in Figure 3. The boundary conditions establish were based on Silva (2014) methodology and applied on the domain to represent a river flow as in Figure 3. A normal velocity $\mathrm{U}_{\infty}=2.5$ was adopted in the inlet, no slip wall for the bed and rotor surface, static pressure zero in outlet and open surface in the sides and top in all cases.

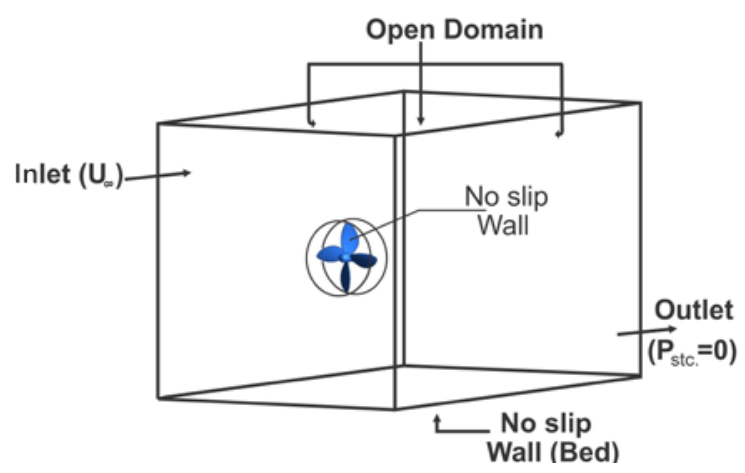

Figure 3. Boundary Conditions.

The next step was the creation of the numerical grid. This process requires precautions given the geometry and dynamics of the rotor, special care at the time of creating the mesh. Therefore, to perform the simulations with the best capacity, an mesh study was employed using ANSYS-CFX/MESH software. Figure 4 and Figure 5 shows the density of elements used to map the blade area and domains. The need for refinement in this region is explained by the high pressure in the rotor due to the interaction of the flow with the blades. The refinement of the rotative domain require more elements than the static one. To secure that the wake regions are well refined, influence sphere were used to improve mesh quality and assist better results.

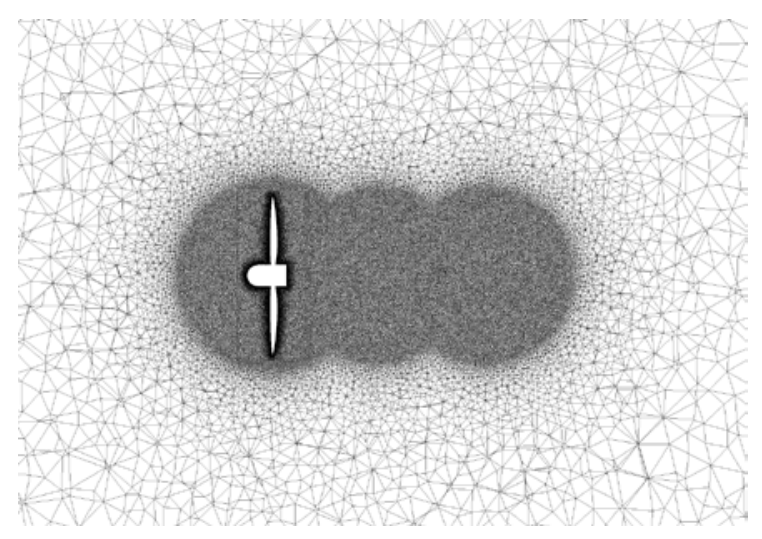

Figure 4. Mesh example.

As the numerical mesh structure directly influences the simulation result, this process becomes iterative, in order to reach the best product. The mesh convergence method was based on monitoring the power $C_{p}$ and velocity in the wake of each mesh, and choose which presented better convergence of these variables. Table 2 present several parameters evaluated during the construction of each mesh. The resolution of the boundary layer, fundamental in simulations. In all of those cases, mesh 3 was chosen to represent the best simulation obtained.

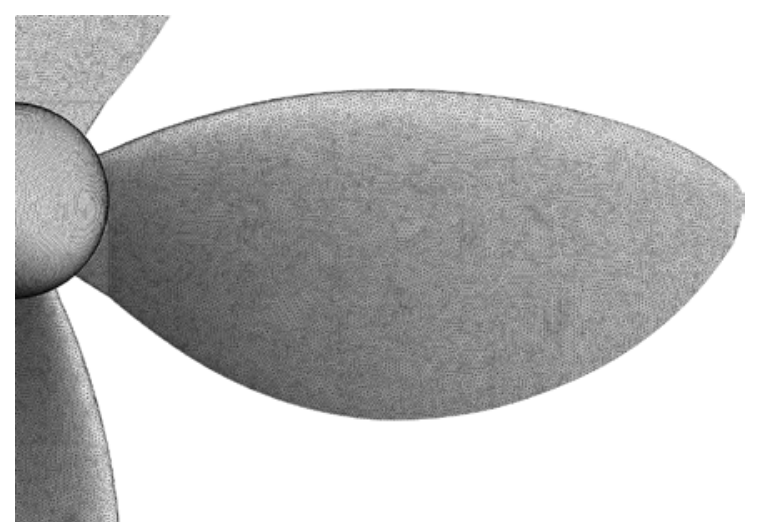

Figure 5. Rotor refinement.

Table 2. Mesh study.

\begin{tabular}{ccc}
\hline & Nodes $\times 10^{6}$ & $C_{p}$ \\
\hline One turbine & 2.28 & \\
1 & 5.57 & 0.367 \\
2 & 7.1 & 0.376 \\
3 & & 0.379 \\
\hline Two Turbines & 3.47 & \\
1 & 4.68 & 0.361 \\
2 & 6.52 & 0.369 \\
3 & & 0.371 \\
\hline
\end{tabular}




\section{WAKE EVALUATION EQUATIONS}

In order to describe the turbulent flow downstream of the turbines there is a need to evaluate the behavior of variations present on the wake. In this way, tools capable of describing the hydrodynamic variables were used. The mean time velocity $(\overline{u(x)})$ of the flow,

$$
\overline{u(x)}=\frac{1}{\Delta t} \int_{\Delta t} u d t^{\prime},
$$

is used to observe the field of velocities around the rotor and the speed recovery. The kinetic energy of turbulence $k$ is another important variable to evaluate the turbulent wake and can be defined by,

$$
k=\frac{1}{2} \sum_{i=1}^{\infty} \overline{\left(u^{\prime}\right)^{2}},
$$

where $u_{i}^{\prime}$ represents the velocity fluctuation ( $u^{\prime}=U-\bar{u}$ ). This can also be defined as half the trace of the Reynolds tensor.

It is also convenient to use the turbulence intensity $(I)$ to define the vigor of the turbulent fluctuations in relation to the average velocity. This definition by Dryen and Kuethe (1930) defines the intensity of turbulence,

$$
|\vec{I}|=\frac{\sqrt{\frac{2}{3} k}}{|\bar{u}|}
$$

where $k$ corresponds to the turbulent energy and $\bar{u}$ can be computed from the three mean velocity components.

\section{RESULTS AND DISCUSSION}

\section{Stand Alone}

For the validation of the adopted methodology, the results of a single turbine were used. The observed parameters show the reproducibility and reliability of the presented simulations. The simulations were performed for a normal inlet velocity of $2.5 \mathrm{~m} / \mathrm{s}$.

Modifying the rotor domain rotation, different blade tip speed (TSR) were obtained, ranging from 0 to 3.5. Was used the results that presented better performance to obtaining the $C_{p} \times T S R$ curve.

Following this analysis, Figure 6 presents the results obtained for the simulation of a stand alone turbine of the present work, comparing them with the results of Brasil Jr. et al. (2016). In the graph it is verified that the performance of the machine remained coherent.

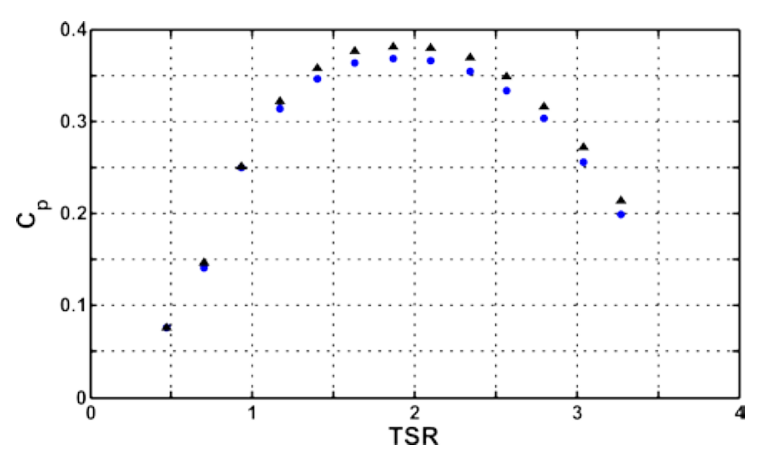

Figure 6. Stand alone turbine $C_{p} \times T S R$. $\boldsymbol{\Delta}$ Brasil

Jr. et al. (2016), • Present Work.

The simulations of this work present conditions of opening and no periodicity in the sides of the domain, considering free flow on the static domain. This can directly influence the results in the power curve when compared to other studies. The purpose of adopting such measures is to represent better the actual conditions of the machines.

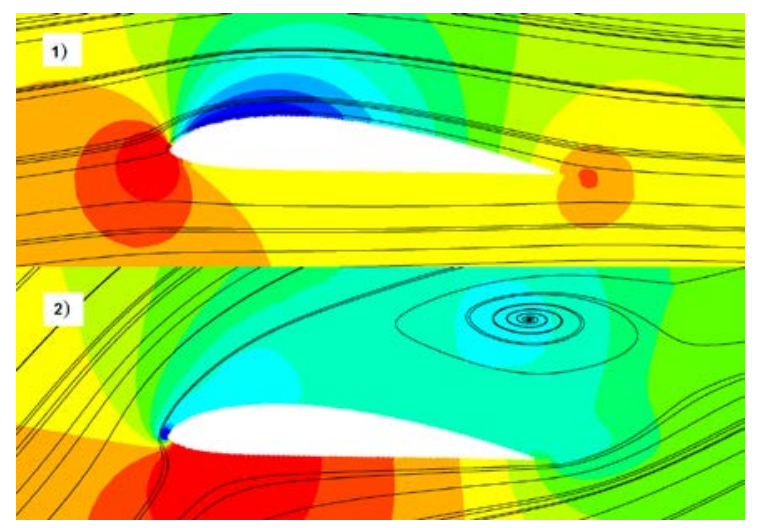

Figure 7. Stand alone blade flow. 1) $T S R=2.34$, 2) $T S R=0.47$.

In the second half of the graph $(T S R \geq 2)$ a difference can be seen when compared to the BEM curve. In this region the flow is fully attached to the blade as shown in Figure 7(1). However, the high rotation causes a velocity reduction in the rotor, generating less power. It changes when the turbine decrease rotation $(T S R \leq 1.2)$. The velocity triangle is modify, causing an augmentation in the attack angle and decreases pressure gradient in the back of the blade. The separation of the flow, represented in Figure 7(2), is characterized by loss of lift due to separation of the flow with the profile. It can also affect the wake due its turbulent characteristics, increasing the production of turbulence behind the rotor. According to this analysis is suggested that the turbine operates in a range of $1.3 \leq T S R \leq 2.5$, to present best performance. 


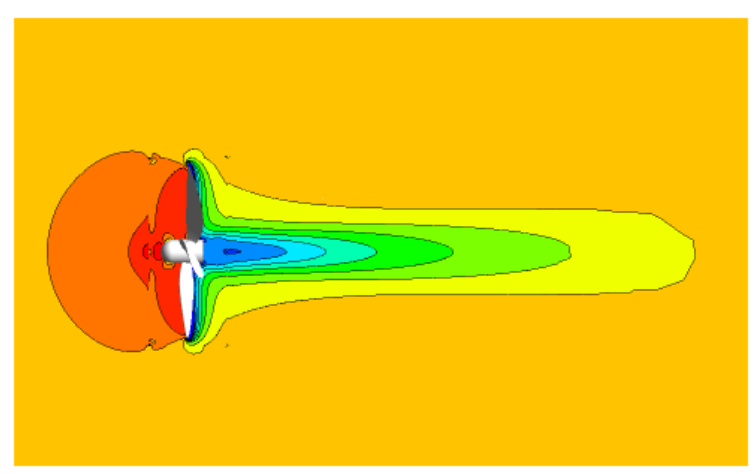

Figure 8. Pressure contour.

The Figure 8 shows the behavior of the pressure upstream and downstream for $\mathrm{TSR}=1.63$. That Tip Speed Ratio is considered better for the operational model of turbine. The region of high pressure, identify in red, is the blockage effect caused by the turbine in the flow. After the rotor, pressure decay forming a sub-pressure zone. This increase and decrease in pressure are predicted by the actuator disk theory and its variation represents the power gained by the rotor. Figure 9 shows how this decay appear for the center line that crosses the rotor, and the pressure recovery of the flow, occurring in only four diameters of the turbine, for the three different rotations.

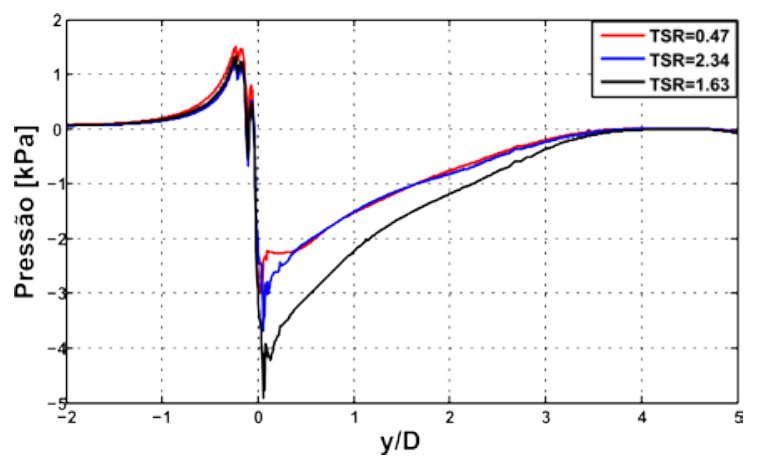

Figure 9. Central line pressure for different TSR.

\section{Row Array}

The row array simulates a sequence of turbines arranged side by side. The objective is to form a hydrokinetic farm. These kind of configuration has been used by other authors observing the blockage effect on the flow, caused by the machines (Whelan et al., 2009; Cooke et al., 2016). As the interest is focused for the interaction between the turbines flow, only a set of two rotors was simulated.

When analyzing the pressure, no specific change was evident when compared to the results presented for a single turbine. It can be seen in the Figure 10 that the blocking effect of the two turbines is similar to that previously observed. However, the streamlines show a central approximation due the presence of the rotors. Possibly the speed up discussed in Brasil Jr. et al. (2016) and Chawdhary et al. (2017), is the result of streamlines constriction given the high pressure in front of the turbines.

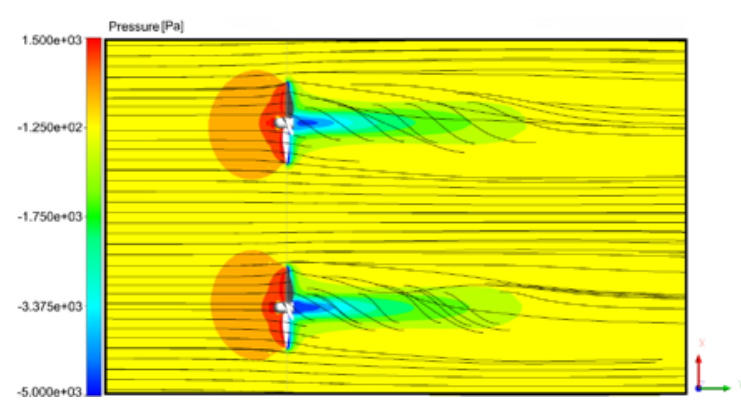

Figure 10. Row array pressure and streamlines.

The streamlines induces the investigation of the velocity field around the turbines. Figure 11 shows the velocity behavior, in which is seen that the rotors cause strong loss of energy in the flow. The contour is normalized by inlet velocity $(2.5 \mathrm{~m} / \mathrm{s})$. In the region behind the rotors there is a severe slowdown (green and blue contours) demonstrating the speed deficit in the wake of the turbine. It is also possible to see the increase in velocity in three regions adjacent to the turbines. Regions where the flow speedup are extended in the central part near the rotors, instigating the relevance of this phenomena.

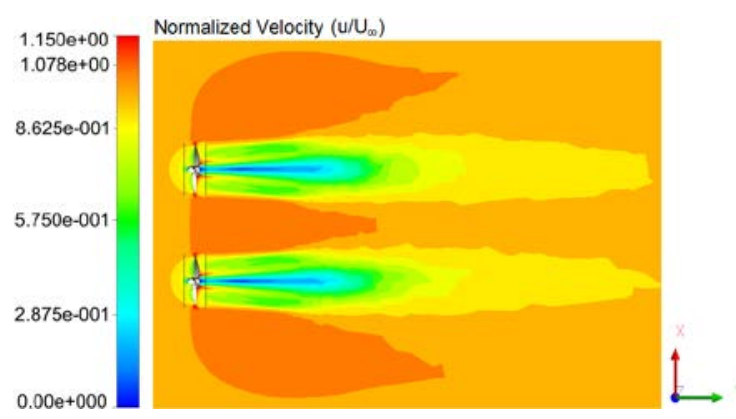

Figure 11. Row array normalized velocity.

The normalized velocity is quantified and presented in graph of Figure 12 for a half diameter distance form the rotors, considered near wake region. The behavior of the graph suggests that the speed increase, as illustrated in the contour above, is located around the rotors. For this distance, the increase in velocity increases between 3\% and \$ 4\% of the inlet velocity. This complement should not be ignored, as the power is directly proportional to the velocity cube. The speed drop caused by the turbine can also be observed, where it is possible to see that the blades cause less flow delay when compared to the hub.

Flow changes are not always positive for the turbines, because even if there is an increase in velocity the turbulent disturbances in the flow can affect the efficiency of downstream rotors. Evaluating the wake is a practical method of 
observing the situations that a downstream turbine may be exposed. Positioning adjustment can prevent turbine-shading areas from causing power loss.

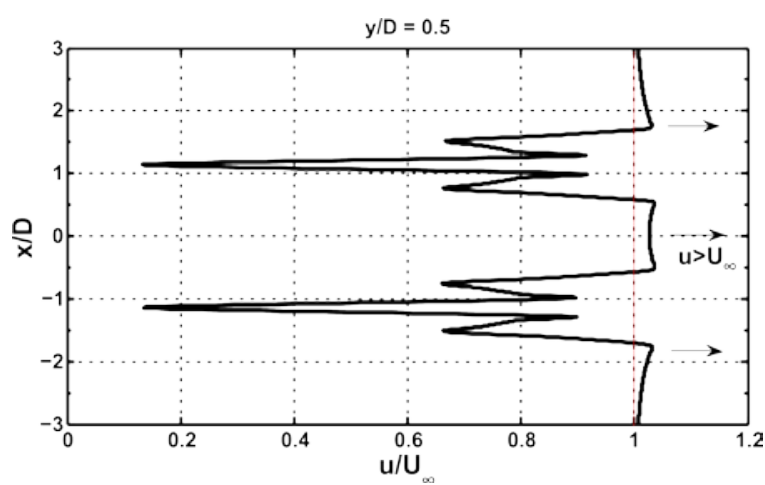

Figure 12. Normalized velocity 0.5 diameter behind turbine.

Therefore it is important to evaluate the Turbulence Intensity and the kinetic energy of turbulence, because, as pressure and velocity, these quantities manifest important characteristics of the flow, especially on the turbulent wake region. Turbulent vortex and Turbulence Intensity are used as the criterion for dynamic loads in turbine situated in the wake (Veisi and Shafiei Mayam, 2017). Turbulence intensity spatial study can minimize the effects of fatigue on downstream machines and optimize the positioning of the hydrokinetic farm.

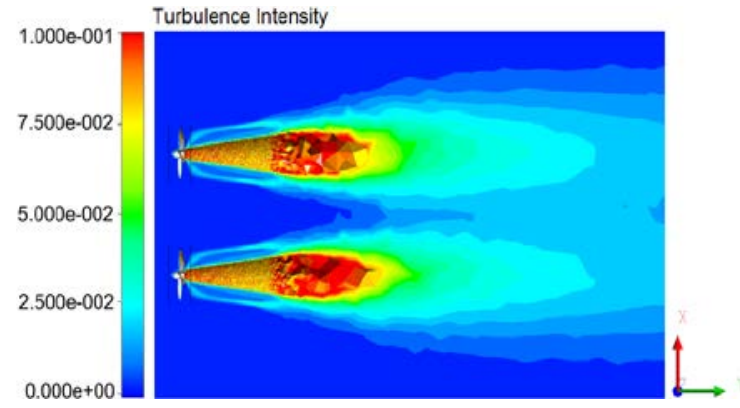

Figure 13. Turbulence Intensity.

Figure 13 shows the flow Turbulence Intensity (IT). The wake behavior indicate that the turbulence starts more vigorous in the central part of the rotor, with slow lateral expansion. The blades contribution support to increase the wake area and the turbulent dissipation in the flow. This situation indicates that the downstream hydrokinetic turbine would experience a more turbulent flow than upstream turbines. Turbulence decreases its intensity by expanding laterally as it distances from the rotor.

To track the turbulent wake, seven lines perpendicular to the flow were used. These lines are distributed as shown in Figure 14. The Turbulence Kinetic Energy (TKE) is recorded as they move away from the rotors. To study the positioning for a possible next array, the wake analysis was performed for up to six diameters downstream of the front turbines.

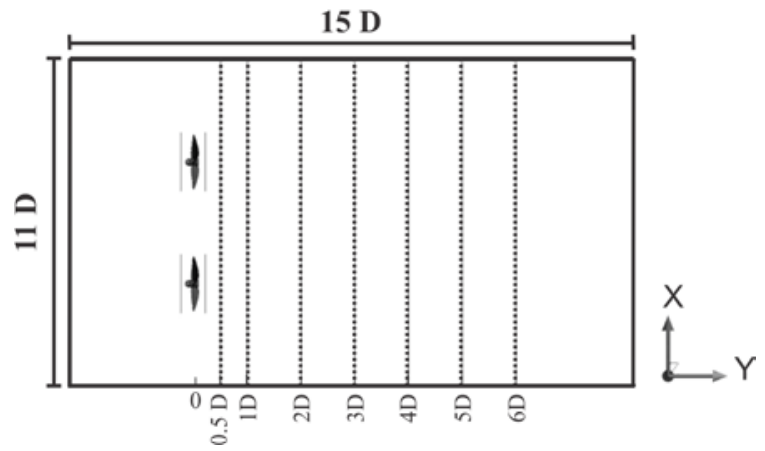

Figure 14. Perpendicular acquisition lines.

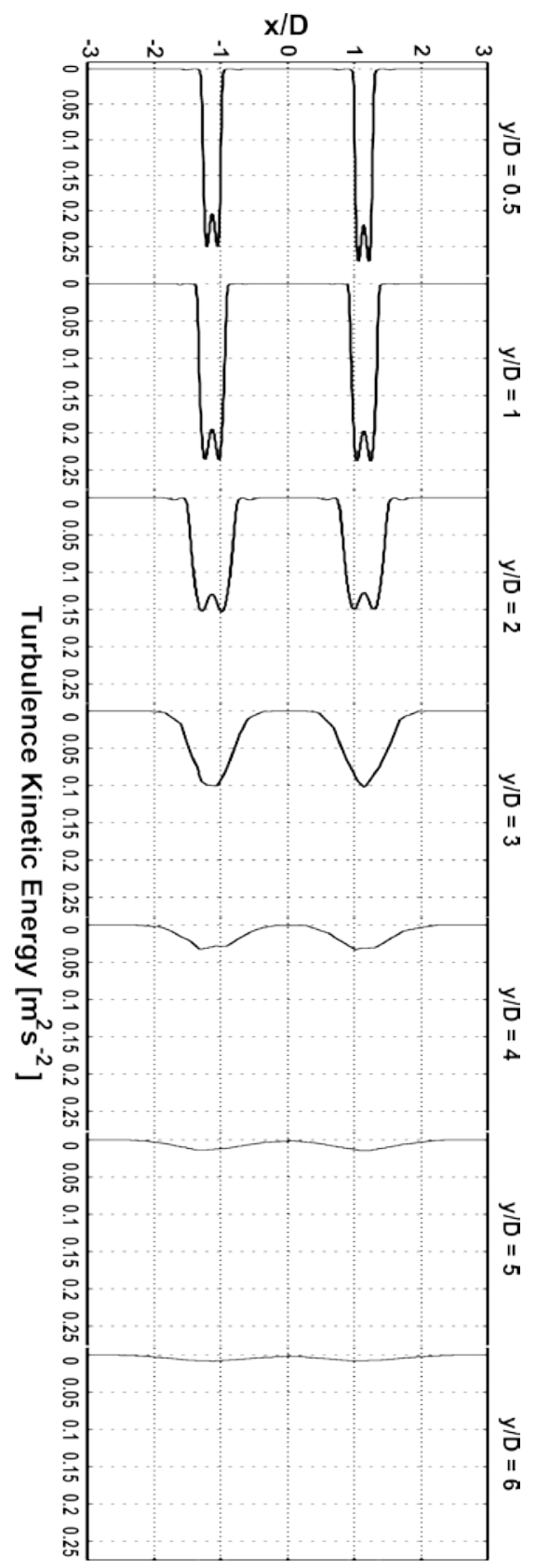

Figure 15. Turbulence kinetic energy wake evolution. 
The Turbulence kinetic Energy evolution is presented in Figure 15. TKE levels upstream are practically null directing the wake study to what happens downstream turbines. By the graphs it can be concluded that the turbulent energy energy have its maximum values close to the rotors dissipating along the domain. This attenuation is due to the viscous turbulent dissipation that transfers energy from large to small scales. The first lines ( $\mathrm{y} / \mathrm{D}=0.5 \& \mathrm{y} / \mathrm{D}=1)$ shows the blade influence on the near turbulent wake.

After two diameters, the TKE levels decay considerably as it expands radially. It is possible to observe that there is interaction between the wake since $\mathrm{y} / \mathrm{D}=3$, making the central flow more turbulent, indicating the impossibility of installing another machine in this position. The central position in this case indicates best benefits for a downstream turbine, it has a central speedup flow and fewer turbulence. However, central positioning should occur up to two diameters, because the low levels of kinetic energy of turbulence tend to cause less fatigue in the turbines downstream.

Can be observed form the graphs and contours that these quantities expand laterally as they move away from the rotors. This lateral spreading can cause some effect on the turbines downstream, harming their efficiency. Up to two diameters in length it is possible to see increase of velocity in the central channel, without the turbulent amounts interfering appreciably in the flow. To guarantee the efficiency of the next row array, it is indicated that downstream turbines should be positioned in the center and up to two diameters of the front pair of rotors.

\section{CONCLUSIONS}

Increasing speed in the middle, between the two turbines, creates the possibility of studying beneficial positions of a rotors system. The turbulence intensity is concentrated in the back regions to the rotors, where they have the peculiarity of growing at half diameter and then decreasing as distance. Observed this it is possible to set a compact hydro farm with greater power efficient.

\section{ACKNOWLEDGEMENTS}

The authors acknowledge with gratitude the support of LEA-UnB laboratory, CAPES and AES Tietê Brasil.

\section{REFERENCES}

Crespo, A., Manuel, F., and Hernandez, J., 1990, Numerical Modelling of Wind Turbine Wakes, in: Proceedings of European Community Wind Energy Conference, Madrid, Spain, pp. 166-170.

Ainslie, J. F., 1988, Calculating the Flow Field in the Wake of Wind Turbines, Journal of Wind
Engineering and Industrial Aerodynamics, Vol. 27, No. 1, pp. 213-224. ISSN 0167-6105.

Bastankhah, M., and Porté-Agel, F., 2014, A new Analytical Model for Wind-Turbine Wakes, Renewable Energy, Vol. 70, pp. 116-123. ISSN 0960-1481.

Betz, A., 1920, Das Maximum der Theoretisch Möglichen Ausnützung des Windes durch Windmotoren, Zeitschrift für das gesamte Turbinenwesen, Heft 26, pp. 307-309. (in German)

Brasil Jr., A. C. P., Mesquita, A., Mendes, R. C. F., and Oliveira, T. F., 2016, On the Hydrodynamics of a Row Arrangement of Hydrokinetic Propeller Turbines, American Journal of Hydropower, Vol. 3, pp. 19-24. ISSN 2317-126X.

Carcangiu, C., 2008, CFD-RANS Study of Horizontal Axis Wind Turbine, Thesis for the Degree of Doctor of Philosophy, Universita Degli Studi di Cagliari.

Chawdhary, S., Hill, C., Yang, X., Guala, M., Corren, D., Colby, J., and Sotiropoulos, F., 2017, Wake Characteristics of a Triframe of Axial-Flow Hydrokinetic Turbines, Renewable Energy, Vol. 109, pp. 332-345. ISSN 0960-1481.

Cooke, S. C., Willden, R. H. J., and Byrne, B. W., 2016, The Potential of Cross-Stream Aligned Sub-Arrays to Increase Tidal Turbine Efficiency, Renewable Energy, Vol. 97, pp. 284-292. ISSN 0960-1481.

Glauert, H., 1935, Windmills and Fans: Aerodynamic Theory, Dover Publications, Vol. 4, pp. 169-360.

Gomez-Elvira, R., Crespo, A., Migoya, E., Manuel, F., and Hernández, J., 2005, Anisotropy of Turbulence in Wind Turbine Wakes, Journal of Wind Engineering and Industrial Aerodynamics, Vol. 93, No. 10, pp. 797-814. ISSN 0167-6105.

Kumer, V. M., Reuder, J., Dorninger, M., Zauner, R., and Grubisic, V., 2016, Turbulent Kinetic Energy Estimates from Profiling Wind Lidar Measurements and their Potential for Wind Energy Applications, Renewable Energy, Vol. 99, pp. 898910. ISSN 0960-1481.

Mehta, D., van Zuijlen, A. H., Koren, B., Holierhoek, J. G., and Bijl, H., 2014, Large Eddy Simulation of Wind Farm Aerodynamics: a Review, Journal of Wind Engineering and Industrial Aerodynamics, Vol. 133, pp. 1-17. ISSN 0167-6105.

Mo, J. O., and Lee, Y. H., 2012, CFD Investigation on the Aerodynamic Characteristics of a Small-Sized Wind Turbine of Nrel Phase Vi Operating with a Stall-Regulated Method, Journal of Mechanical Science and Technology, Vol. 26, No. 1, pp. 81-92. ISSN 1976-3824.

Mycek, P., Pinon, G., Lothodé, C., Dezotti, A., and Carlier, C., 2016, Iterative Solver Approach for Turbine Interactions: application to Wind or Marine Current Turbine Farms, Applied Mathematical Modelling. ISSN 0307-904X.

Potsdam, M., and Mavriplis, D., 2009, 
Unstructured Mesh CFD Aerodynamic Analysis of the Nrel Phase Vi Rotor, in: 47th AIAA Aerospace Sciences Meeting including The New Horizons Forum and Aerospace Exposition, American Institute of Aeronautics and Astronautics, Aerospace Sciences Meetings. doi:10.2514/6.2009-1221.

Sanderse, B., van der Pijl, S. P., and Koren, B., 2011, Review of Computational Fluid Dynamics for Wind Turbine Wake Aerodynamics, Wind Energy, Vol. 14, No. 7, pp. 799-819. ISSN 1099-1824.

Silva, P. A. S. F., 2014, Estudo Numérico de Turbinas Hidrocinéticas de Eixo Horizontal, Master Thesis, Departamento de Engenharia Mecânica, Universidade de Brasília, Brasília, DF. (in Portuguese)

Sorensen, J. N., and Shen, W. Z., 2002, Numerical Modeling of Wind Turbine Wakes, Journal of Fluids Engineering, Vol. 124, No. 2, pp. 393-399. ISSN 0098-2202.

Troldborg, N., Sorensen, J. N., and Mikkelsen, R., 2010, Numerical Simulations of Wake Characteristics of a Wind Turbine in Uniform Inflow, Wind Energy, Vol. 13, No. 1, pp. 86-99. ISSN 10991824.

Veisi, A. A., and Shafiei Mayam, M. H., 2017, Effects of Blade Rotation Direction in the Wake Region of Two Inline Turbines Using Large Eddy Simulation, Applied Energy, Vol. 197, pp. 375-392. ISSN 0306-2619.

Vennell, R., 2010, Tuning Turbines in a Tidal Channel, Journal of Fluid Mechanics, Vol. 663, pp. 253-267. ISSN 0022-1120.

Whelan, J. I., Graham, J. M. R., and Peiró, S., J., 2009, A Free-Surface and Blockage Correction for Tidal Turbines, Journal of Fluid Mechanics, Vol. 624, pp. 281-291. ISSN 0022-1120.

Wilson, R. E., and Lissaman, P. B. S., 1974, Applied Aerodynamics and Wind Power Machines, NASA STI/Recon Technical Report N, Report No. NSF-RA-N-74-113, NTIS, Springfield, Virginia. 